\title{
Empowering communities to make pregnancy safer: An intervention in rural Andhra Pradesh
}

Dipa Sinha

Follow this and additional works at: https://knowledgecommons.popcouncil.org/departments_sbsr-rh

Part of the Demography, Population, and Ecology Commons, Family, Life Course, and Society Commons, International Public Health Commons, Maternal and Child Health Commons, and the Women's Health Commons How does access to this work benefit you? Let us know!

\section{Recommended Citation}

Sinha, Dipa. 2008. "Empowering communities to make pregnancy safer: An intervention in rural Andhra Pradesh," Health and Population Innovation Fellowship Programme Working Paper no. 5. New Delhi: Population Council. 

This report is the result of a project entitled "Safe Motherhood through Community Mobilisation," undertaken as part of the Health and Population Innovation Fellowship (HPIF) awarded to the author in 2004.

The HPIF programme is administered by the Population Council, New Delhi and is a continuation of the MacArthur Foundation's Fund for Leadership Development (FLD) fellowship programme that continued over the period 1995 to 2004. The Council is grateful to the MacArthur Foundation for its support to this programme.

The HPIF programme aims to support mid-career individuals who have innovative ideas, leadership potential, and the capacity to help shape policy and public debate in the field of population, reproductive health and rights in general, with a focus on two priority themes maternal mortality and morbidity, and the sexual and reproductive health and rights of young people. Since the transfer of the programme to the Population Council through 2006, a total of 17 individuals have been supported under the HPIF programme.

\section{For additional copies of this report, please contact:}

Dipa Sinha

C-II/97 Moti Bagh

New Delhi 110021

Email: dipasinha@gmail.com
Population Council

Zone 5A, Ground Floor

India Habitat Centre,

Lodi Road, New Delhi 110003

Phone: 011-2464 2901/02

Email: info-india@popcouncil.org

Web site: http://www.popcouncil.org/asia/india.html

The Population Council is an international, non-profit, non-governmental organisation that seeks to improve the well-being and reproductive health of current and future generations around the world and to help achieve a humane, equitable and sustainable balance between people and resources. The Council conducts biomedical, social science and public health research, and helps build research capacities in developing countries.

\section{Copyright (C) 2008 Dipa Sinha}

About the author: Dipa Sinha has a M.Sc. in Development Studies from the School of Oriental and African Studies, University of London, an M.A. in Economics from Jawaharlal Nehru University and a BA (Hons.) in Economics from the University of Delhi. She is associated with the M.V. Foundation, Andhra Pradesh, working on the issue of child labour and child rights.

Suggested citation: D. Sinha. 2008. "Empowering Communities to Make Pregnancy Safer: An Intervention in Rural Andhra Pradesh," Health and Population Innovation Fellowship Programme Working Paper, No. 5. New Delhi: Population Council.

\section{(P) Population Council}




\section{Empowering Communities to Make}

Pregnancy Safer

\section{AN INTERVENTION \\ IN RURAL \\ ANDHRA PRADESH}

Dipa Sinha

Fellow

Health and Population Innovation Fellowship Programme 


\section{Contents}

List of tables and figures ___ iv

Introduction 1

Background __ 3

The intervention site and project design __ 4

The intervention area___ 4

Description of the intervention 7

Community organisers _ 7

Project design _ـ 7

Initiatives at the community level _ـ 10

The intervention_ 10

Gram panchayats and youth committees as agents of change __ 11

Outcomes 12

Awareness of health as a community need _ 12

Accountability of health service providers and partnerships with providers _ 13

Community involvement in pregnancy care __ 17

Initiatives at the level of the family _ 19

The intervention__ 19

Outcomes 20

Recognition of the need for family support to pregnant women _ 20

Family-level changes as perceived by community members and community organisers _ 21

Family involvement in pregnancy-related care _ 22

Initiatives at the level of pregnant women 24

The intervention__ 24

Outcomes 25

Awareness of healthy practices during pregnancy _ 25

Pregnancy-related practices _ 26

Delivery-related practices _ 30

Summary and recommendations __ 32

Summary __ 32

Recommendations _ 33

References _ 35

Acknowledgements __ 36 


\section{List of tables and figures}

Table 1: Profile of Andhra Pradesh, Rangareddy district and Mominpet mandal 6

Table 2: Maternal health situation in Andhra Pradesh and Rangareddy district 6

Table 3: Changes in the quality of health services, as perceived by women, at endline $(\mathrm{N}=501)$ 16

Table 4: Community-level changes, as perceived by women, at endline $(\mathrm{N}=501)$

Table 5: Family support to recently delivered women, as reported by women at baseline and endline, and at endline by women who had more than one pregnancy resulting in a live birth

Table 6: Birth planning: Women who recalled information provided by a community organiser on selected topics, at endline $(\mathrm{N}=501)$ 26

Table 7: Nutrition practices during pregnancy, as reported by women at baseline and endline, and at endline by women who had more than one pregnancy resulting in a live birth

Table 8: Antenatal practices, as reported by women at baseline and endline, and at endline by women who had more than one pregnancy resulting in a live birth

Table 9: Planning for delivery, as reported by women at baseline and endline 30

Table 10: Place of delivery, as reported by women at baseline and endline, and at endline by women who had more than one pregnancy resulting in a live birth

Map 1: Andhra Pradesh state, Rangareddy district and Mominpet mandal 5

Figure 1: Antenatal care-related information provided to husbands: Women whose husbands had attended group meetings and had shared the proceedings with their wives, at endline $(\mathrm{N}=134)$

Figure 2: Women reporting type of support received from husband during pregnancy, at baseline and endline

Figure 3: Antenatal care awareness: Women who recalled information provided by a community organiser on selected topics, at endline $(\mathrm{N}=501)$

Figure 4a: Work that was reduced or completely stopped during pregnancy as reported by women at baseline and endline

Figure 4b: Work that was reduced or completely stopped during pregnancy as reported by women at endline who had more than one pregnancy resulting in a live birth 


\section{Introduction}

Pregnancy and childbirth are a privileged function of women, essential for the survival of our species. Women have a right, a basic human right, to be protected when they undertake the risky business of pregnancy and childbirth. Society has an obligation to fulfil a woman's right to life.

Women are not dying during pregnancy and childbirth because of conditions that are difficult to manage. They are dying because the societies in which they live did not see fit to invest what is needed to save their lives. (Fathalla, 2004)

Despite unprecedented economic growth in India over the last decade, maternal mortality and morbidity continue to be unacceptably high. More than 100,000 mothers in the country die each year as a result of pregnancy-related causes (UNICEF, n.d.). One study reports that for each maternal death, 15-20 mothers suffer from serious childbirth-related health impairments (Datta et. al., 1980), while another study estimates that "for every death, a further 30 to 50 women will survive the same complications but be left with short- or long-term disability if not treated properly and on time" (DFID, 2004). Maternal heath and pregnancy-related care remain poor; according to the National Family Health Survey (NFHS)-3, in the three years preceding the survey, over half of all deliveries $(52 \%)$ in the country took place without trained assistance and more than half (58\%) of all pregnant women aged 15-49 were anaemic (IIPS, 2007b). Neonatal mortality - a direct outcome of poor maternal heath and pregnancy-related care-remains high (IIPS, 2007b). What makes the situation more disturbing is that most maternal deaths are avoidable (Bhatia, 1993; UNFPA, 2002). Poor maternal health outcomes and pregnancy-related care are rooted in structural factors such as poverty and illiteracy, as well as other factors including lack of awareness of appropriate health practices and prompt decision-making, lack of family support for pregnant women, limited access to health facilities and poor quality of care at available facilities (Jejeebhoy, 2000). The situation is compounded by the practice of early marriage and pregnancy in adolescence in many parts of India (Jejeebhoy, 2000).

As in India, the maternal health situation in Andhra Pradesh is of concern. While the maternal mortality ratio in Andhra Pradesh (195 per 100,000 births) is lower than the average for India (301 per 100,000 births) (RGI, 2006), skilled attendance at delivery more widespread and infant mortality about as high, these levels are far from acceptable. ${ }^{1}$ Indeed, a study conducted in rural Andhra Pradesh concluded that 78 percent of reported maternal deaths could have been prevented by the provision of basic pregnancy-related services, such as, for example, antenatal care, skilled attendance at delivery and emergency obstetric care (Bhatia, 1993).

1 According to the NFHS-3 fact sheets, the proportion of institutional deliveries in the three years preceding the survey in Andhra Pradesh was 69 percent as compared to 41 percent nationally; and the infant mortality rate during the same period was 53 per 1,000 births in Andhra Pradesh as compared to 57 per 1,000 births nationally (IIPS, 2007a; 2007b). 
Recognising that multiple factors are responsible for adverse pregnancy-related outcomes, a community-based intervention was implemented in Mominpet, a mandal ${ }^{2}$ in Andhra Pradesh in collaboration with the M.V. Foundation, a non-governmental organisation. The intervention focused on improving maternal health outcomes by raising awareness and building family and community support for pregnant women; involving pregnant women's families, notably their husbands, in pregnancy-related care; and supporting pregnant women to access health services.

This report describes the experience and outcomes of the intervention. In particular, it explores the extent to which the intervention was effective in increasing community support for safe motherhood on the one hand, and in improving pregnancy-related practices on the other. It describes the activities undertaken during the project period, and discusses outcomes at the level of the community, the family and pregnant women based on qualitative and survey data. Finally, it suggests recommendations for policy and programmes based on lessons learnt from the intervention.

\footnotetext{
2 A mandal is an administrative unit comprising of about 30-40 villages and an average population of about 40,000-60,000. At any given point of time there are 300-400 pregnant women in a mandal.
} 


\section{Background}

A review of the literature suggests that factors that influence maternal health operate both at the level of the health system, and at the level of the individual, the family and the community. At the level of the health system, the lack of accessible health facilities is a key obstacle in accessing maternal health care; indeed, in many areas, health facilities are located at a distance, and are not connected by a proper road or transport facilities, which lead to delays in accessing timely care during delivery (Thaddeus and Maine, 1994). Further, even where health centres or hospitals are accessible and available, they are often under-staffed, or are not properly equipped in terms of facilities and supplies, including medical supplies and a blood bank. Where services are available, they are provided at a cost that may not be affordable to the poor. Moreover, studies have shown that provider attitudes towards the poor and unsatisfactory quality of care at facilities also act as deterrents to the poor accessing health services (Jejeebhoy and Varkey, 2004).

At the level of the individual woman, several interrelated factors adversely influence maternal health outcomes, including women's poor nutritional status and diet, the practice of early marriage and childbearing, women's limited awareness of healthy practices and their limited autonomy within the family (Bloom, Wypij and Das Gupta, 2001; Jejeebhoy, 2000). Indeed, in many settings in India women have limited access to resources, including food, health care and education, which is a significant barrier to positive pregnancy-related outcomes (Rama Padma, 2005).

Key factors that operate directly or indirectly at the level of the family include awareness among senior family members of pregnancy-related care, the extent of husbands' involvement in pregnancy-related care and the willingness of the family to invest in good health practices and care during pregnancy (McCarthy and Maine, 1992; Sugathan, Mishra and Retherford, 2001). Studies show that in rural India, pregnancy and maternal care are considered to be exclusively a woman's domain; an attitude that often excludes men from participating in routine maternal and pregnancy care (Barua et al., 2004). Further, although men might be uninvolved and uninformed, they are significant decision-makers with regard to pregnancy-related care and expenditure (Khan, Khan and Mukherjee, 1997); it is therefore important to involve men in any programme that aims to improve pregnancy-related care and maternal health.

Attitudes at the community level, by and large, mirror the perceptions of family members towards pregnancy-related care. Indeed, the family-level obstacles noted above, including gender norms, are similarly reflected at the community level. Pregnancy and childbirth continue to be perceived as issues in the private domain, essentially a woman's concern, which do not require community initiatives. Ensuring accountability from the government health service delivery mechanism is not perceived to be the responsibility or the right of the community. However, a study in Karnataka has shown that the community can exert pressure on health providers by actively participating in the service delivery process and extending support to them (FRHS, 2004). 


\section{The intervention site and project design}

\section{The intervention area}

The intervention was undertaken in collaboration with the M.V. Foundation, a non-governmental organisation that focuses on child rights issues in Andhra Pradesh. The Foundation works on issues concerning child labour and education. Its activities focus on abolishing child labour and mainstreaming children into the formal school system. For example, to enable older children to join school at a level appropriate to their age, the Foundation organises bridge course camps through the accelerated learning programme. The Foundation has also taken up cases of child abuse and child marriage in the community.

To achieve its objectives of abolishing child labour and universalising elementary education, the Foundation works with the local community to sensitise them to the issue of child rights. The Foundation also partners with local groups, such as gram panchayats, school education committees and youth groups, to mobilise parents to send their children to school. The Foundation undertook this project to work on the rights of children under 6 years and their mothers. As a result of their work, the Foundation has been recognised by the community as a child rights organisation.

The intervention was piloted in Mominpet mandal, one of the 37 mandals in Rangareddy district, Andhra Pradesh (Map 1). Mominpet mandal consists of 20 gram panchayats ${ }^{3}$ and 38 villages, and has a population of about 40,000 . The intervention covered all the communities in 37 villages. In Mominpet village, which is the mandal headquarters of Mominpet, activities focused only on the poorer localities.

The socio-demographic profile of Mominpet mandal suggests that by and large, it is less developed than either Rangareddy district or the state as a whole. As evident from Table 1, Mominpet is an entirely rural area, and the large majority of its working population is engaged in agricultural activities. The mandal reports a larger gender gap in literacy, a larger scheduled caste population and a larger asset-less population than both the district and the state.

3 Gram panchayats are elected local government bodies in rural India. Each gram panchayat covers one or more villages depending on the size of the population. 
Map 1:

Andhra Pradesh state, Rangareddy district and Mominpet mandal
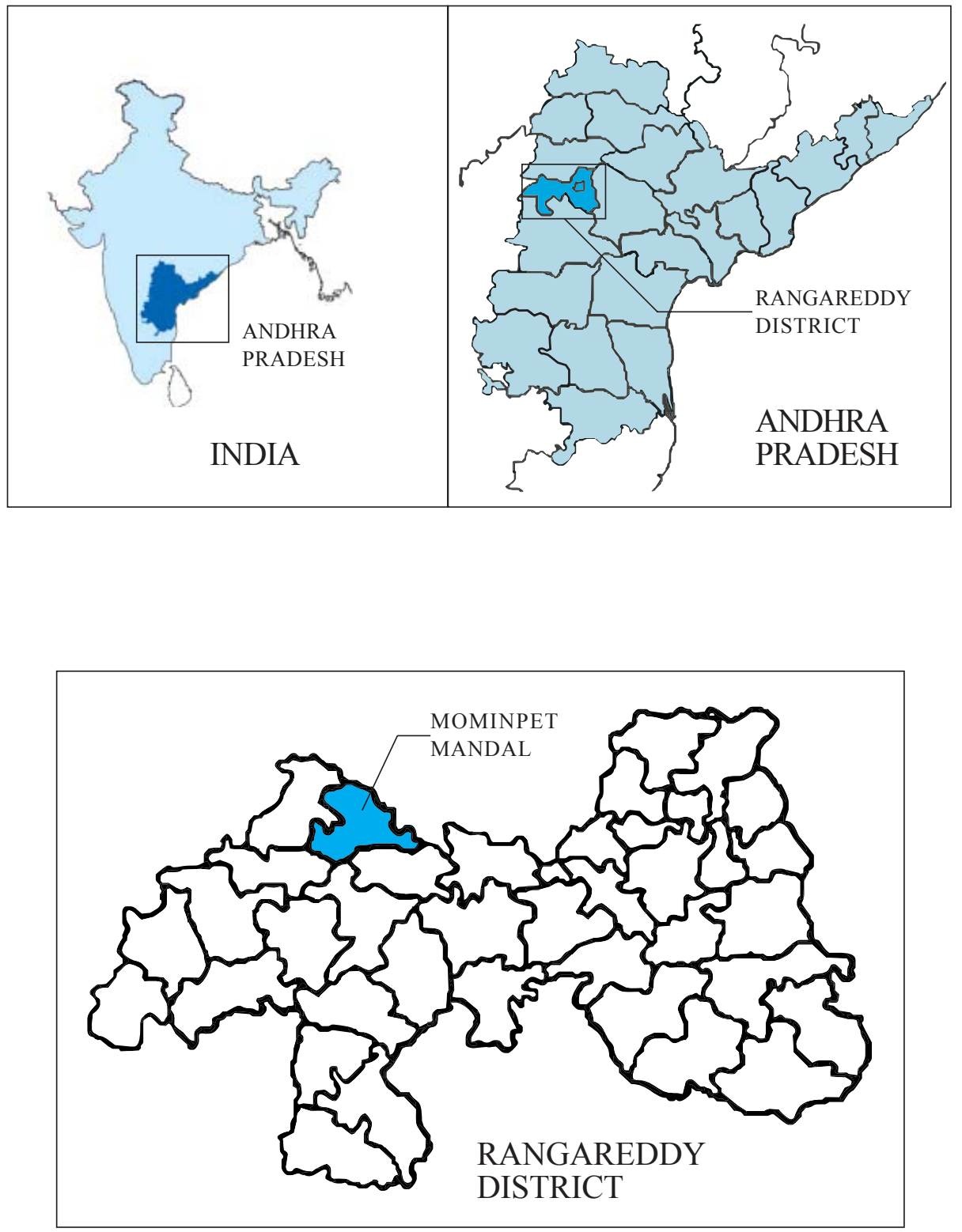

Source: Adapted from www.mapsofindia.com; rangareddy.nic.in

Note: Maps are not drawn to scale. 
Table 1:

Profile of Andhra Pradesh, Rangareddy district and Mominpet mandal

\begin{tabular}{|c|c|c|c|}
\hline Characteristic & $\begin{array}{l}\text { Andhra } \\
\text { Pradesh }\end{array}$ & $\begin{array}{l}\text { Rangareddy } \\
\text { district }\end{array}$ & $\begin{array}{l}\text { Mominpet } \\
\text { mandal }\end{array}$ \\
\hline Urban population (\%) & 27.3 & 54.2 & 0 \\
\hline $\begin{array}{l}\% \text { population working in the } \\
\text { agricultural sector }\end{array}$ & 75.0 & 69.3 & 87.3 \\
\hline Total literacy rate & 60.5 & 66.2 & 51.1 \\
\hline Gender gap in literacy* & 21.9 & 24.5 & 26.9 \\
\hline$\%$ population scheduled caste & 18.4 & 20.6 & 28.0 \\
\hline $\begin{array}{l}\% \text { households owning none of the following } \\
\text { six consumer goods: bicycle, four wheeler, } \\
\text { two wheeler, radio, television and telephone }\end{array}$ & 53.2 & 51.2 & 67.2 \\
\hline
\end{tabular}

Source: RGI, $2001 \mathrm{a} ; 2001 \mathrm{~b}$.

* Male literacy rate minus female literacy rate.

As mandal level data on the maternal health situation are not available, Table 2 presents comparative data only for Rangareddy district and Andhra Pradesh. Findings suggest that the maternal health situation in Rangareddy district is fairly typical of the state on average.

Table 2:

Maternal health situation in Andhra Pradesh and Rangareddy district

\begin{tabular}{|l|c|c|}
\hline Characteristic & $\begin{array}{c}\text { Andhra Pradesh* } \\
(\mathbf{2 0 0 5 - 0 6 )}\end{array}$ & $\begin{array}{c}\text { Rangareddy district** } \\
\text { (2002-04) }\end{array}$ \\
\hline $\begin{array}{l}\text { \% of women who received any } \\
\text { antenatal care during last pregnancy }\end{array}$ & 96.0 & 91.2 \\
$\begin{array}{l}\text { \% of women who reported an } \\
\text { institutional delivery for last birth }\end{array}$ & 69.0 & 64.1 \\
\hline
\end{tabular}

Source: *IIPS, 2007a; **PRC, 2000.

In terms of health infrastructure, Mominpet mandal has one primary health centre, which is open round-the-clock, and nine sub-centres. There are no private nursing homes or clinics in the mandal; the nearest town, Sadashivpet, where such facilities are available is located about $10 \mathrm{~km}$ from the mandal headquarters. The nearest district hospital is located at a distance of $20 \mathrm{~km}$ from Momimpet mandal, in Sangareddy in Medak district. 


\section{Description of the intervention}

The objective of the intervention was to raise awareness of healthy pregnancy-related practices and support access to health services. Intervention activities focused on three levels: that of the community, the family and pregnant women. At the community level, the intervention sought to make maternal health a public concern, creating an environment that enabled women, especially during pregnancy, to access nutrition, rest and medical support. The intervention also aimed to mobilise communities to exercise pressure on the existing health system, through gram panchayat and youth committee meetings, making them more accountable. At the family level, during home visits and through group meetings, family members were apprised of how to take special care of pregnant women and help them access health care services. At the level of the individual, the intervention raised awareness among pregnant women about pregnancy-related care, antenatal care, institutional delivery and risk factors, and empowered them to access appropriate care.

\section{Community organisers}

Activities were conducted by local field-level staff, known as community organisers. The M.V. Foundation selected residents of Mominpet mandal, who were accepted by the community and had a commitment to social issues, to work as organisers. These organisers were experienced in community mobilisation and were recognised within Mominpet mandal for their work with the M.V. Foundation on the protection of child rights.

Most community organisers had 10 years of schooling. They were skilled in bringing people together and working with them to initiate change. Moreover, as the team of community organisers had worked with the Foundation for a few years prior to the intervention, they had the advantage of knowing the local residents and of having established a rapport with members of local bodies such as the gram panchayats, youth groups and mahila mandals. As a result of their work at the Foundation, community organisers had also established a reputation for being honest and dependable, which contributed to the acceptability of the intervention activities.

Prior to initiating the intervention, community organisers underwent training on issues related to maternal health. Through these organisers, the project established a link between pregnant women, their families and the community; pregnant women and the health system; and the community and the health system.

\section{Project design}

A pre- and post-intervention design was selected to assess the effectiveness of the programme in building awareness in the community on maternal health and improving pregnancy-related practices. The limitations of this design are well-known; we acknowledge that the findings are illustrative and not conclusive, and that changes observed may not be attributed with certainty to the intervention. 
The baseline survey was conducted in September 2004 and covered all women who had delivered in the 12 months prior to the survey. The endline survey was conducted 18 months later, in April 2006. Successive cross-sections of women who had delivered in the previous 12 months were interviewed. ${ }^{4}$

The sample selection strategies varied in the baseline and endline surveys. Prior to the baseline survey, a complete household listing was undertaken that identified all women who had delivered in the previous year. A total of 667 such women were identified; in order to provide a representative assessment of the baseline situation, the study aimed to cover half this sample. A two-stage sampling process was implemented. In the first stage, three-quarters of all villages in the mandal, i.e., 28 of 38 villages, were randomly selected. In the second stage, individual, systematic random sampling was employed using the list of eligible households as the sampling frame. A total of 20 eligible women were to be interviewed from each large village selected (population more than 2,000) and 12 from each small village selected (population less than 2,000). In some villages, this strategy required that all eligible women identified were interviewed; in a few, the allocated sample size could not be reached due to the non-availability of eligible women. Using this strategy, the baseline survey covered a total of 319 recently-delivered women.

For the endline survey, in contrast, all available and consenting women who had delivered in the previous one year were interviewed in order that the entire intervention population was represented. In this case, the household listing and survey were conducted simultaneously. In the course of house-listing, all identified women who had experienced a delivery in the previous 12 months were interviewed. A total of 501 women were thus interviewed of an estimated total of 700 from the house-to-house survey, or a response rate of about 70-75 percent. Non-response was largely attributed to two factors: one, some women had returned to their natal homes for delivery during the survey period; two, as the survey was undertaken during the school vacations, several women had left the village to visit relatives in other areas.

In addition to the endline survey, in-depth interviews were conducted with six gram panchayat members, six youth committee members, two auxiliary nurse-midwives (ANMs) and the medical officer at the Mominpet primary health centre to assess their perspectives on the usefulness of the intervention.

Baseline and endline survey instruments were, by and large, identical. The questionnaire covered, for example, the socio-demographic characteristics of the woman and her family; women's awareness and perceptions of key issues related to maternal health and pregnancy, antenatal care, delivery and post-natal care; experiences relating to the last pregnancy; and perceptions about community participation in maternal health and community support to pregnant women. Baseline and endline survey questionnaires differed, however, in two respects. First, in the endline survey, respondents were asked to

4 The profile of the respondents was the same; in both cases women who had delivered in the 12 months preceding the survey were interviewed. However, since it is unlikely that all the women who had delivered during the baseline survey would have delivered again, it is not the same set of women who were interviewed during the endline. 
report their experiences in both the most recent pregnancy as well as the penultimate one (for those who had experienced more than one delivery) in order to explore whether pregnancy-related practices had changed; these questions were answered by 289 of the 309 women who had more than one pregnancy. ${ }^{5}$ Second, in order to assess the reach and perceived quality of the intervention, the endline survey questionnaire included an additional module covering women's experiences of the intervention, women's recall of information provided by their husbands on their participation in intervention activities, women's recall of pregnancy-related messages provided by community organisers, and women's and community members' perceptions of change in family and community support over the course of the intervention.

In the following sections, findings from the qualitative and survey data on project lessons and their outcomes are discussed. Project outcomes were measured in two ways. First, baseline and endline survey responses were compared to assess the extent to which pregnancy-related practices had indeed improved at the conclusion of the project. Additionally, women's and husbands' contact with the intervention and their recall of messages related to maternal health imparted during the intervention were assessed. Second, to asses change over the intervention period, perceptions about changes in community attitudes to pregnancy-related care and maternal health were sought from women in the course of the endline survey, and from key community persons in the course of in-depth interviews.

5 Excluded were five women whose previous pregnancy resulted in an abortion; 10 whose previous pregnancy and live birth ended in an infant death; one whose pregnancy ended in a still birth; and four who did not answer. 


\section{Initiatives at the community level}

\section{The intervention}

Given the short duration of the project, initiatives at the community level focused on members who could play a key role in the short term in improving maternal health outcomes and making pregnancy safer. Intervention activities were designed to include, for example, gram panchayat members and youth who could influence families and women as well as demand accountability from health service providers, ANMs who are directly involved in providing health services, and teachers and headmasters who are respected members who could mobilise attitudinal change. To address transport-related obstacles in accessing hospital services in an emergency, auto rickshaw drivers were also mobilised to provide transport without delay, and on credit if necessary, to pregnant women.

The intervention mobilised community members to demand quality pregnancy-related services and to build community support for pregnant women to access appropriate care. Community organisers conducted initial discussions with women, gram panchayat members, youth committee leaders as well as other members of the community to understand prevailing pregnancy-related practices and perceptions. Discussions revealed that pregnancy was perceived as a normal event in the life of a woman, and one in which the community did not have a role to play. For instance, the community did not show any concern if a woman had to deliver under a tree because a doctor was not available at the health facility, or if a maternal or newborn death occurred. Moreover, members of the community were unaware of their right to access public health services or their right to monitor these services and demand better quality care. As a result of prevailing traditional norms, communities tended to discount the need to invest in women's health and well-being. The lack of community awareness of appropriate pregnancy-related care constituted a significant barrier inhibiting women from accessing services to which they are entitled and, as a result, antenatal care, supplementary nutrition and iron supplements did not reach all pregnant women, skilled attendance at delivery was uncommon and postpartum care rare.

The intervention made multiple efforts to mobilise the community to recognise women's right to access health care, to address traditional norms surrounding pregnancy-related care and to raise awareness of women's rights. Community organisers conducted activities through two established community groups - gram panchayats and youth committees. Regular public meetings were organised to link the health system and the community. Rallies, campaigns, cultural programmes and street plays were also organised at the village and mandal levels to raise community awareness of maternal health issues. In addition, posters on issues such as the right of pregnant women to access services, the importance of institutional delivery and the legal minimum age at marriage were widely displayed. 


\section{Gram panchayats and youth committees as agents of change}

One of the first tasks of the intervention was to raise awareness among gram panchayat members and youth committee leaders of the powerful role they could play in ensuring that public health facilities provide the services that they are required to deliver. Community organisers trained gram panchayat members and youth committee leaders on the role of public institutions in service delivery, their right to question the functioning of public health facilities and the ways in which the performance of health care providers in public institutions could be monitored. Community organisers also provided every sarpanch (headman) and youth committee leader with a document that outlined the role of each health-related government institution and the services the institution was obliged to deliver; sarpanchs and youth committee leaders were made aware of how to use this document as a monitoring tool during review meetings held with government staff.

As a result of the activities of the project, a system was established whereby the gram panchayat held regular meetings to review the functioning of public health providers and facilities, including ANMs and anganwadi centres. Representatives of local bodies/organisations, including ward members, ${ }^{6}$ anganwadi workers, headmasters, ANMs, and members of school, youth and mothers' committees were invited to attend, and the activities of each institution reviewed at the meeting. The maternal and child health situation in the mandal was also reviewed, and information collected on the number of deliveries, complicated deliveries and maternal deaths that had taken place; the number of deliveries conducted at home and in a facility; the provision of antenatal care and immunisation; newborn, infant and child mortality; and the number of malnourished children.

Meetings were held at least once a month in eight of the 20 gram panchayats and once every alternate month in another 12 gram panchayats. In all, about 200 such meetings were held during the reporting period. In addition, similar meetings were held at the mandal level.

At review meetings members often engaged in heated debates regarding the delivery of health services. Review meetings were also a forum where members discussed the prevailing situation, and took action in cases where services were not appropriately provided, for example, when the ANM had been found to be irregular, the anganwadi centre was not opening on time, or too many pregnant women were being referred to the district hospital for delivery. A non-confrontationist approach was adopted during these meetings; efforts were made to ensure that both community members and health and other service providers were given an opportunity to share their views and problems. In a few instances where there was no change even after repeated warnings during the meetings, the review committee succeeded in initiating action with higher authorities. Over the course of the project, sarpanchs began conducting the review meeting independently, and did not need to depend on community organisers to brief them on the issues to be discussed.

6 The area under a gram panchayat is sub-divided into wards. Each ward elects a ward member who then becomes a member of the gram panchayat. 
Community organisers supported youth committee leaders to build awareness among youth of the need to make health service providers accountable to the community. Meetings were organised with young people at the village level to inform them about the duties of public health providers, including anganwadi workers, ANMs and primary health centre staff, and to review their performance. Youth meetings were held every alternate month in all the 38 villages in the mandal. About 300 meetings were held during the intervention period.

As all members of village level youth committees were men, community organisers helped youth groups to set up committees of girls and young women. Interestingly, members of male-dominated youth committees helped to overcome the obstacles to girls' participation at these meetings; they convinced parents to permit their daughters to attend the meetings and assured them that they would provide a safe environment for girls. Young women's committees aimed not only to discuss and build awareness about such issues as child marriage and pregnancy-related care among women and girls, but also to encourage them to participate actively in youth committees along with men, and to engage in activities to apply pressure on primary health centre staff to build accountability. Committees of girls and young women were formed in about 20 villages.

Indeed, as a result of mobilisation efforts, young people themselves argued for a forum at the mandal level where they could discuss issues and put pressure on the existing health service facilities for improved service delivery. Participants at youth meetings expressed a commitment to monitor the functioning of health facilities, and sought to initiate a forum at the mandal level that would assess the functioning of the primary health centre and seek accountability from the staff. In response, a mandal-level meeting was held with youth representatives from all the villages and a Youth Committee for the Right to Health established. The committee proposed to meet every month and make regular visits to the primary health centre to ensure that the staff were present and the patients well served. About 10 such committee meetings were held during the intervention period.

\section{Outcomes}

\section{Awareness of health as a community need}

Gram panchayat and youth committee members reported that, following project activities and review meetings, they had become sensitised to consider health an important community need. According to one gram panchayat member:

Earlier I was concerned about issues such as education, jobs, water, etc. I was not really concerned about health. When I participated in the recent [health] campaign activities, I felt there was a lot to be done regarding health. Right now, as a Mandal Parishad Territorial Committee [MPTC] member, I am making every effort to ensure that buildings are sanctioned for sub-centres. We want to ensure that every village has access to an ANM. (Gram panchayat member, male, 54 years) 
A youth community member shared similar experiences:

When the community organiser asked us to support him in the health programme, we thought there was nothing we could do to help him. We felt it was something they [community organisers] had to do-to go and speak to the women. But slowly we understood. We formed a committee. We went and met the ANM and the doctor in the primary health centre. We told them that they should be regular; we also told them we would help them. In some cases we even helped the community organiser to make home visits and organise village meetings. (Youth committee member, male, 20 years)

Indeed, as a result of growing awareness of the need to address health issues, members of the gram panchayat had raised funds from the community to meet health emergencies.

We collected funds at the gram panchayat meeting. We use these funds when there is an emergency. (Gram panchayat member, male, 36 years)

Youth committee members similarly made efforts to raise funds to improve health facilities. A sum of Rs. 16,000 was collected from the community, as well as donations in kind such as fans, chairs, benches, bedsheets, tube lights and bulbs. A joint committee comprising primary health centre staff and youth representatives was established to oversee the use of these funds.

\section{Accountability of health service providers and partnerships with providers}

Following mobilisation efforts, the community was more likely to put pressure on public health providers to ensure their accountability. For example, at review meetings held by the gram panchayat over the intervention period, members often questioned ANMs and anganwadi workers about their irregular attendance at the health facility. Similar strategies were adopted at General Body Meetings ${ }^{7}$ to ensure accountability from doctors and primary health centre staff. At these meetings, sarpanchs raised concerns, such as the lack of skilled personnel in the primary health centre at all times to conduct a delivery, the erratic availability of ambulances and the irregular attendance of ANMs, in the presence of primary health centre doctors and other government officials.

In a few instances where health workers continued to attend to their duties irregularly, gram panchayat members reported the issue to their supervisors.

We questioned them [ANMs and medical officers] in the gram panchayat meeting. We told them that if they did not want to do their job well, they should resign and leave this place. We even wrote to the District Medical and Health Officer and asked him to take necessary action. (Gram panchayat member, male, 33 years)

7 General Body Meetings are held by the government once in three months at the mandal level with gram panchayat members from the mandal and officials from all the government departments operating at the mandal level. 
In cases where the community was unable to elicit an appropriate response from concerned officials, delegations of sarpanchs, youth and other members of the community met with the District Collector as well as the District Medical and Health Officer to petition for assistance. For example, as the following quote indicates, gram panchayat members made repeated visits to district officials to demand equipment, staff and other facilities necessary to make the sub-centres and the primary health centre functional.

\section{We talked to the District Medical and Health Officer several times about the need for equipment such as a blood pressure apparatus, the shortage of ANMs, and the primary health centre not functioning properly. Although we mentioned these issues each time, nothing happened. We had to go eight times... Then they provided medicines and a blood pressure apparatus. (Gram panchayat member, male, 42 years)}

In addition to ensuring that staff at the public sector health facilities were accountable to the community, gram panchayat and youth committee members also tried to address the genuine obstacles that were expressed by health care providers, including lack of equipment and supplies and the difficulty in arranging transport for pregnant women. In these cases, community members interacted directly with government officials to resolve the problem.

She [the primary health centre doctor] told us that there was no staff nurse, there was a water problem in the hospital, and no staff to conduct urine and blood tests. Then we met the Mandal Parishad President [MPP], the Mandal Revenue Officer [MRO] and the District Medical and Health Officer and handed them a petition. (Youth committee member, male, 22 years)

She [the ANM] told us about the problems they face.... there are not enough medical supplies and pregnant women are not coming to the hospital regularly. Based on this information, we wrote to the District Medical and Health Officer. We even met the health officials directly and told them about the problems that people are facing because of lack of resources at the primary health centre. (Gram panchayat member, male, 36 years)

Indeed, community leaders reported that as a result of direct interaction with government officials on problems faced by health providers and the women themselves, there was more openness among officials to resolving issues and a greater willingness to accept feedback from the community. For example, at review meetings, one problem repeatedly highlighted was that several women were being unnecessarily referred to the District Hospital when they sought deliveries at the primary health centre. Gram panchayat members brought this problem to the attention of the primary health centre staff and were apprised of the poor facilities in the primary health centre and the inability of the staff to cater to unforeseen delivery-related complications; at the same time, the medical officer assured them that every effort would be made to minimise unnecessary referrals. Such interaction not only led to a better understanding between community members and primary health centre staff, but also motivated communities to apply pressure on government staff to provide the necessary services at the level of the primary health centre. 
Similarly, appreciating the problems articulated by the medical officer, youth groups mobilised young people in the community to improve facilities at the primary health centre. Youth leaders, in coordination with local elected representatives and hospital staff, organised a shramdaan (voluntary labour programme) at the primary health centre with young people from the mandal. Activities focused on cleaning the surroundings of the primary heath centre. According to a youth committee member:

We spoke to the doctor and demanded that she take good care of the people. She talked about how dirty the hospital was, that it was overgrown like a jungle. Then we [youth committee members] organised a meeting with community organisers. We collected young people from all the villages and organised a cleaning campaign in the hospital. About 50 youth participated. We removed the bushes, and even cleaned the toilets. Then we told the doctor that we had done "shramdaan" [voluntary work] and cleaned the hospital. We said, "Now it is your turn. Please give time and take care of pregnant women." She said she would do her best. (Youth committee member, male, 20 years)

Indeed, regular review meetings not only ensured the proper functioning of health facilities and staff, but also provided health functionaries an opportunity to share their problems and the obstacles they faced in performing their duties and providing services. This, in turn, helped the community to appreciate providers' difficulties.

We attend gram panchayat meetings regularly. We respond to whatever queries the authorities [sarpanch, MPTC] in the meetings may have.... Earlier, when we told people that medicines were out of stock, they would react adversely. They would say that we were selling the medicines and making money. But now, as all these issues are discussed in gram panchayat meetings and we report on everything, people are also aware of the situation. They are more understanding of our problems now. (ANM, female, 35 years)

These strategies appear to have had positive results. Several gram panchayat and youth members reported that the primary health centre staff were attending to their duties more regularly, and the need to be accountable to the community was better accepted by the staff. For example:

Earlier the ANM thought that if she came once a week and did "namaste" to the sarpanch, her work was done. Now she is doing all her work properly. The people are also questioning her. She attends to her work regularly and takes care of those who are unwell. She gives medicines, follows up on every pregnant woman and immunises children. (Gram panchayat member, male, 40 years)

Because we did all this [questioning public health facility staff in gram panchayat meetings], ANMs and doctors come on time and do their work properly. (Gram panchayat member, male, 33 years)

We are ensuring that ANMs work properly. Now even the doctors are doing their duty regularly. (Gram panchayat member, female, 45 years) 
Youth committee members likewise reported that activities such as regular committee meetings and frequent visits to the primary health centre had resulted in more accountability among health staff, better quality services at facilities and improved care by providers at the primary health centre. As noted in the following quotes, the doctor at the primary health centre has begun residing in the staff quarters and has discontinued her private practice, reflecting to some extent the pressure generated at the community level.

Earlier she [the ANM] would come from another village. She would always be late. Then some young people went and spoke to her. She has now rented a house close by. Now she is working well. There is no problem. (Youth committee member, female 18 years)

Someone from our village would visit the primary health centre at least twice a week. Sometimes, when the doctor was not there, we would ask the ANM where she was. We would be told that she had gone for a meeting. All the youth representatives met the doctor and asked her why she was never in the health centre. She said that she had to come from a distance and therefore was not able to reach on time. Then we asked her to stay in Mominpet. There are quarters for her here. Since then she has been staying here and taking care of emergencies as well. (Youth committee member, male, 19 years)

Women also perceived that health care providers had become more responsive to the needs of pregnant and newly-delivered women following intervention activities (see Table 3). For example, 63 percent of all women noted that compared to two years prior to the survey, the ANM attends to her duties more regularly and is more responsive, and 57 percent agreed that a doctor/nurse is available at all times in the primary health centre. Likewise, 53 percent perceived an improvement in the quality of services provided at the primary health centre.

\section{Table 3:}

Changes in the quality of health services as perceived by women at endline $(\mathrm{N}=501)$

\begin{tabular}{l|c|c|c|}
$\begin{array}{l}\text { \% of women reporting that compared to } \\
\text { two years prior to the survey: }\end{array}$ & Agree & Disagree & $\begin{array}{c}\text { Can't } \\
\text { say }\end{array}$ \\
\hline $\begin{array}{l}\text { The ANM is more regular and responsive } \\
\begin{array}{l}\text { A doctor/nurse is more likely to be available at } \\
\text { all times in the primary health centre }\end{array}\end{array}$ & 63.1 & 19.4 & 17.2 \\
$\begin{array}{l}\text { The quality of services provided at the primary } \\
\text { health centre has improved }\end{array}$ & 53.1 & 16.6 & 30.1 \\
\hline
\end{tabular}




\section{Community involvement in pregnancy care}

As a result of project activities, community commitment to addressing obstacles to improved pregnancy care increased. For example, gram panchayat members played a proactive role in campaigning for institutional deliveries and addressing some of the problems that the community faced in obtaining these services. In many gram panchayats, the sarpanch issued a letter to all traditional birth attendants asking them not to conduct deliveries at home but rather, to accompany women to the primary health centre or hospital. Some sarpanchs even called a meeting of all auto rickshaw drivers in the village and instructed them to take women to hospital when they were in labour. Drivers were also asked not to bargain with the family when the woman had to be taken for delivery, and if necessary, to settle payment after the delivery took place.

There are four auto rickshaws in our village. Even if it is in the middle of the night, the auto rickshaw driver will take a woman in labour to the hospital very carefully. If the woman is critical, the auto driver will even take her to Sangareddy [the nearest district hospital, which is $20 \mathrm{~km}$ from Mominpet mandal]. We even organised meetings of auto drivers. The auto drivers have responded well and they take women to the hospital in time. (Gram panchayat member, male, 40 years)

Youth committee members also supported sarpanchs in efforts to ensure that affordable and timely transport was available to women in labour.

There are autos available at all times in our village to take women in labour to either Mominpet or Sangareddy. We organised a meeting with the auto drivers in our village and fixed the rate for taking women to hospital. We went to the MPTC and told all the auto owners that in all circumstances they must agree to take the woman to hospital at the fixed rate. They have agreed. (Youth committee member, male, 22 years)

\section{Table 4:}

Community-level changes as perceived by women at endline $(\mathrm{N}=501)$

\section{$\%$ of women reporting that compared to two years prior to the survey:}

There is more discussion in the village on issues related to child health and safe delivery

More people in the village are talking about maternal health

People in the village are more concerned about the safety of pregnant women

The community is more committed to improving maternal health

The gram panchayat is more active in supporting women during pregnancy/delivery to ensure a safe delivery

\begin{tabular}{|c|c|c|}
\hline Agree & Disagree & $\begin{array}{c}\text { Can't } \\
\text { say }\end{array}$ \\
\hline 64.3 & 14.3 & 21.3 \\
\hline 55.7 & 16.8 & 27.3 \\
\hline 52.9 & 21.2 & 25.7 \\
\hline 47.9 & 30.7 & 21.0 \\
\hline 2.8 & 53.3 & 23.6 \\
\hline
\end{tabular}


Women perceived greater community support for pregnancy-related care following project activities. For example, 53 percent of women agreed that, as compared to two years prior to the survey, community members are more concerned about the safety of pregnant women. Moreover, the majority (65\%) reported that there is more discussion in the community on issues related to child health and safe delivery. Similarly,

56 percent of women agreed that more people in the community are now talking about maternal health. Fewer than half $(48 \%)$ agreed that the community is more committed to improving maternal health and 23 percent of women also noted that the gram panchayat is now more active in supporting women to ensure safe delivery (Table 4). 


\section{Initiatives at the level of the family}

\section{The intervention}

Intervention activities at the family level were mainly directed to husbands and senior family members, notably mothers-in-law. In the course of visits to pregnant women's homes, community organisers sought to raise awareness among family members, build family members' commitment to providing appropriate care to pregnant women, and ensure that the family supported pregnant women to access institutional delivery or skilled attendance at birth. During the third trimester, organisers assisted family members in making specific plans for women's deliveries, including planning transport, preparing birth plans and setting aside money for delivery-related costs or in case of an emergency.

Mothers-in-law were approached, by and large, in the course of house visits and community organisers faced little resistance from them. A few meetings were also organised for mothers-in-law over the intervention period. However, it became clear, in the course of the intervention, that husbands were a more difficult group to reach effectively during home visits as compared to mothers-in-law or other women in the family. Husbands, for example, perceived that pregnancy-related messages were relevant only for their wives or other women, and many refused to participate in discussions during home visits. Most husbands were willing to allow their wives to obtain antenatal care services, many would readily provide for the purchase of medicines and some even accompanied their wives to the doctor, especially those who went to a private doctor. However, the large majority perceived that their involvement and responsibility ended there; they were unwilling to assume a more proactive or supportive role at home and appeared embarrassed to discuss pregnancy-related issues with community organisers, directing them, rather, to their wives or mothers.

In order to break down this reticence among husbands and involve them in discussions, the project initiated a strategy other than home visits to reach this group. Meetings were held outside the home that brought together husbands and gave them space to open up and discuss maternal health issues, including ways in which they could support their pregnant wives. Attendance was erratic at first but gradually improved; by the time the endline survey was conducted, husbands' meetings were being held regularly - at least once in two months - in every village. Over the intervention period, a total of about 125 meetings with husbands were held.

Meetings and home visits with husbands and other family members focused on three issues. First, discussions were held on the ways in which husbands could support their pregnant wives: topics included the acceptability of and need for husbands to provide support including doing housework, insisting that their wives eat nutritious food and planning for an institutional delivery. Second, husbands were apprised about facility-level issues, for example, available services, the availability of doctors/nurses at all times of the day and the need to plan transport in case of an emergency. Finally, issues relating to domestic violence, harassment and husband's alcoholism were also discussed. In cases 
where pregnant women talked about experiencing such problems, rather than taking on these issues directly in the home, community organisers raised these problems as general matters of concern during meetings with husbands or mothers-in-law, taking special care to ensure the presence of members of the particular family at the meeting. Community organisers also made efforts to counsel husbands privately.

Members of gram panchayats and youth committees also attended group meetings and shared their experiences. The quality of care received at the sub-centre or primary health centre during antenatal visits and at delivery were discussed, and husbands, gram panchayat members and youth committee members together planned action in case of poor quality of care or mistreatment.

\section{Outcomes}

\section{Recognition of the need for family support to pregnant women}

The majority of women ( $79 \%$ and $60 \%$, respectively) reported that a community organiser had discussed pregnancy-related care with their husbands and mothers-in-law during home visits and group meetings (not shown in tabular form). Although these visits and meetings had raised awareness among family members about pregnancy care and the need to support women through pregnancy and childbirth, changing husbands' attitudes was not an easy task. It was clear that efforts to make husbands more supportive questioned deep-rooted norms and beliefs, and met with considerable resistance; consequently, husbands were slow to change their views. Indeed, even though community organisers regularly assembled husbands together at group meetings to discuss issues related to pregnancy care, many women $(65 \%)$ reported that their husbands were not aware of these meetings or had not attended a meeting even once. Nevertheless, of the women whose husbands had attended one or more meetings $(\mathrm{N}=175$, or $35 \%)$, the majority $(84 \%)$ reported that group meetings were useful and recommended that they be continued (not shown in tabular form).

Of the 175 women whose husbands had attended the group meetings, most (77\%) said that their husbands had shared with them the proceedings of the meeting: 74 percent reported that their husbands had discussed issues relating to diet and nutrition, 62 percent said their husbands had discussed the need for pregnant women to rest and 54 percent noted that their husbands had been told about place of delivery (Figure 1).

Attendance at group meetings appeared to enhance solidarity among husbands, many of whom agreed to counter traditional norms and contribute to housework; reduce alcohol use and spend, rather, on improving the nutritional status of their pregnant wives; and accompany their wives for pregnancy-related services. Often, during meetings, men who had attended one or more previous meetings described the ways in which they had supported their pregnant wives, providing role models for other husbands as well. However, several women reported that while their husbands were willing to contribute to housework, they were apprehensive of the reaction of their parents, neighbours and others to men becoming engaged in what is perceived as women's work. 


\section{Figure 1:}

Antenatal care-related information provided to husbands: Women whose husbands had attended group meetings and had shared the proceedings with their wives, at endline $(\mathrm{N}=134)$

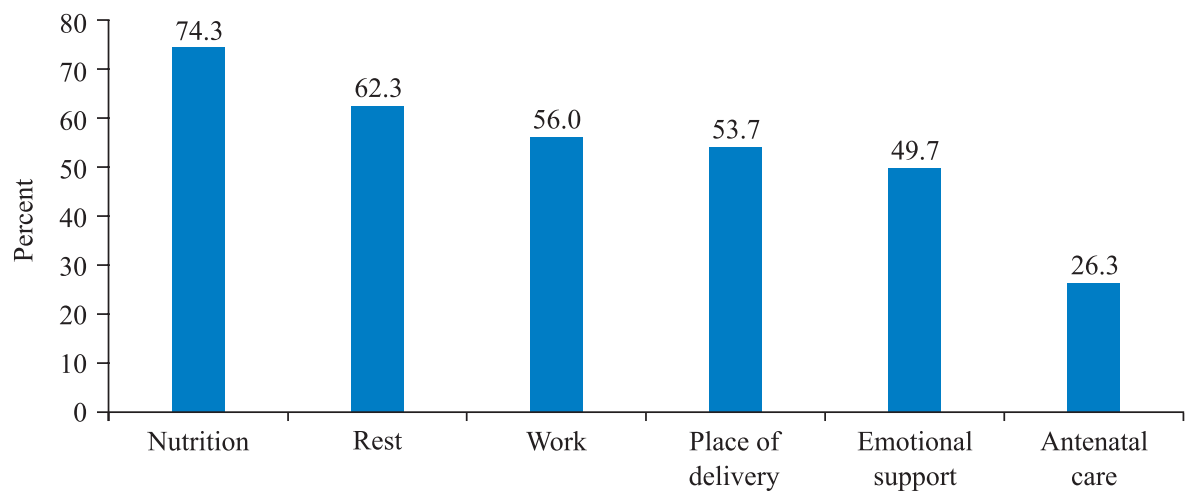

Note: As reported to women by their husbands.

\section{Family-level changes as perceived by community members and community organisers}

Although husbands were a difficult to reach group during home visits, gram panchayat and youth committee members noted that sustained interaction had raised awareness among husbands and other family members of the need for appropriate pregnancy-related care, which had resulted in greater family support for pregnant women.

In the beginning they [husbands] would scold us. They would say, "How is it possible not to give them [pregnant women] work? Who will do all the work? Then we will have to do the housework as well as the outside work. Isn't that difficult for us? We cannot bring better [nutritious] food; as it is, it is difficult to fill our stomachs." They would get angry and say, "Do you expect us to wash our wives'clothes?" But we were patient. We told them that because there was no family support, children were being born weak. We gave them case studies of infant and maternal deaths due to lack of support in the family. We explained to them how their lives and their children's lives would be affected if they were not supportive during pregnancy. Then they understood. Their awareness increased. Now they are taking good care of their wives. (Gram panchayat member, male, 36 years)

There was a lot of opposition from them [husbands and mothers-in-law]. Some even became abusive. They would say, "How does it bother you if I make my wife or daughter-in-law work. Do you have some relationship with her?" Some husbands said, "If my wife doesn't work in the field, how will we run the house? Will you feed us?" We tried to explain in a way that they would understand. We told the husband that if he wanted his child to be healthy, then he should take care of his wife. We 
talked to them patiently and motivated them. Now many [husbands] have changed. They are also learning from the example of others. They are taking good care of their wives to ensure that their children are healthy. (Youth committee member, male, 22 years)

Community organisers also reported a change in husbands' willingness to discuss their wives' pregnancies during home visits following project activities; husbands' attitudes had shifted from a reluctance to get involved in women's issues ("Why do we need a meeting? It is their [women's] issue") to demonstrating genuine concern and support.

\section{Family involvement in pregnancy-related care}

Findings suggest that family involvement in pregnancy-related care did increase, though modestly, over the course of the intervention. For example, among women who reported that their husbands had attended one or more meetings (35\%), 58 percent said that their husbands had become more supportive of them after the meetings (not shown in tabular form). Similarly, while 51 percent and 31 percent of women reported at baseline that their husbands and mothers-in-law, respectively, had accompanied them to seek antenatal care, these proportions increased to 54 percent and 36 percent, respectively, by endline (Table 5). Women who had experienced an earlier pregnancy reported likewise a change over the two pregnancies: from 47 percent in the previous pregnancy to 52 percent during the most recent one.

\section{Table 5:}

Family support to recently-delivered women as reported by women at baseline and endline, and at endline by women who had more than one pregnancy resulting in a live birth

\begin{tabular}{|l|c|c|c|c|}
\hline \multirow{2}{*}{ \% of women reporting: } & \multicolumn{2}{|c|}{ All respondents } & \multicolumn{2}{|c|}{$\begin{array}{c}\text { Women reporting more } \\
\text { than one birth }\end{array}$} \\
\cline { 2 - 5 } & $\begin{array}{c}\text { Baseline } \\
(\mathbf{N}=\mathbf{3 1 9})\end{array}$ & $\begin{array}{c}\text { Endline } \\
(\mathbf{N}=\mathbf{5 0 1})\end{array}$ & $\begin{array}{c}\text { Past delivery } \\
(\mathbf{N}=\mathbf{2 8 9})\end{array}$ & $\begin{array}{c}\text { Most recent } \\
\text { delivery } \\
(\mathbf{N}=\mathbf{2 8 9})\end{array}$ \\
\hline $\begin{array}{l}\text { Husband accompanied } \\
\text { them for antenatal care }\end{array}$ & 50.9 & $54.0^{*}$ & 47.2 & $52.4^{* *}$ \\
\hline $\begin{array}{l}\text { Mother-in-law accompanied } \\
\text { them for antenatal care }\end{array}$ & 30.5 & $35.7^{*}$ & 28.5 & 28.5 \\
\hline
\end{tabular}

${ }^{*} p \leq 0.1,{ }^{*} p \leq 0.05$ 


\section{Figure 2:}

Women reporting type of support received from husband during pregnancy at baseline and endline

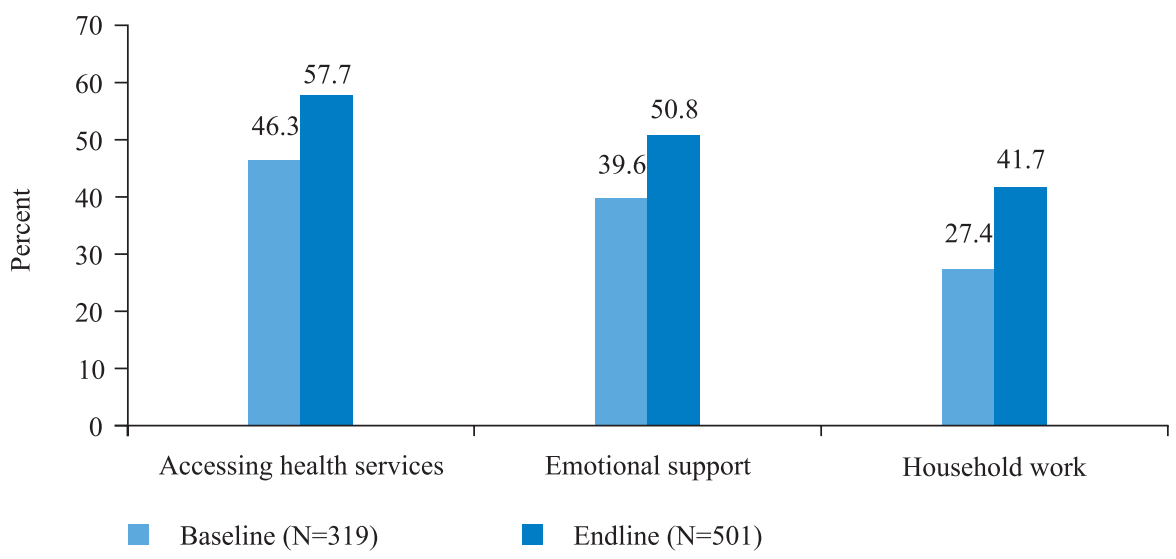

Larger percentages of women at endline than at baseline reported other ways in which they had received support from the family, notably, their husbands. For example, while only 27 percent respondents reported at baseline that their husbands had provided help with household work during their pregnancy, by endline the proportion of women reporting that they had received such help was considerably higher-42 percent (see Figure 2). Somewhat similar patterns were observed with regard to husbands providing support in terms of accessing health care services and providing emotional support. 


\section{Initiatives at the level of pregnant women}

\section{The intervention}

Over the course of the intervention, community organisers made multiple efforts to identify pregnant and newly-delivered women. Organisers visited all households in which women in the reproductive age group resided in order to identify pregnant women in the mandal. They also worked closely with anganwadi workers (who are required to keep a record of all pregnant and newly-delivered women) and other community members to identify pregnant women in the area. Pregnant women not listed in the records of the anganwadi workers or ANMs were encouraged to register with them.

Community organisers also acted as intermediaries between pregnant women and health services. Organisers made regular home visits to pregnant women; those in their first and second trimester were visited at least twice a month and those in their third trimester were visited at least once a week. They also informed women about the date of the ANM's visit to the village and ensured that women accessed the ANM during these visits to obtain such services as immunisation (tetanus toxoid) and iron and folic acid tablets.

To raise awareness of healthy pregnancy-related practices, community organisers visited pregnant women at home and counselled them on the need for proper nutrition and rest. Women were also motivated to visit the primary health centre for at least three antenatal checkups. Breastfeeding was emphasised and following delivery, community organisers made efforts to ensure that breastfeeding was initiated as soon as possible. Community organisers also informed women of their availability at any time if they found themselves in difficulty, or if they were in labour and needed assistance to reach a health facility. In some cases, they accompanied women for pregnancy-related services, including, occasionally, for the delivery, if requested, or in cases where women had no family support.

In addition, community organisers made efforts to ensure that pregnant women could access quality care. For example, if a woman in labour was referred to a higher level facility, the organiser ensured that transport was arranged and timely. If appropriate procedures were not followed - for example, if a dai (traditional birth attendant) was observed to conduct deliveries in the primary health centre or if hospital staff attempted to extract payment from women or their families - community organisers would intervene.

As the intervention progressed, pregnant women began to identify themselves to community organisers and by the end of the intervention, most pregnant women in Mominpet mandal had been reached by the intervention.

In total, over the period September 2004 to March 2006, 1,177 pregnant women were identified; of these, 45 reported having experienced a miscarriage or abortion, 861 had delivered during the project period and 271 women were still pregnant at the conclusion of the project. 


\section{Outcomes}

\section{Awareness of healthy practices during pregnancy}

The majority of respondents ( $85 \%$ of women interviewed at endline) reported that a community organiser had visited them at home during their pregnancy. Of these, 56 percent reported that an organiser had convinced them of the need for antenatal care, and 8 percent reported that an organiser had accompanied them when they sought antenatal care (not shown in tabular form).

During home visits, community organisers raised awareness among pregnant women about issues related to pregnancy-related care. As can be seen from Figure 3, most women recalled that community organisers had provided information on appropriate diet $(72 \%)$, antenatal care $(70 \%)$, adequate rest $(69 \%)$ and the need for an institutional delivery $(63 \%)$. Fewer women, in comparison, recalled messages relating to danger signs during pregnancy $(46 \%)$ and the importance of making a delivery plan $(45 \%)$.

\section{Figure 3:}

Antenatal care awareness: Women who recalled information provided by a community organiser on selected topics at endline $(\mathrm{N}=501)$

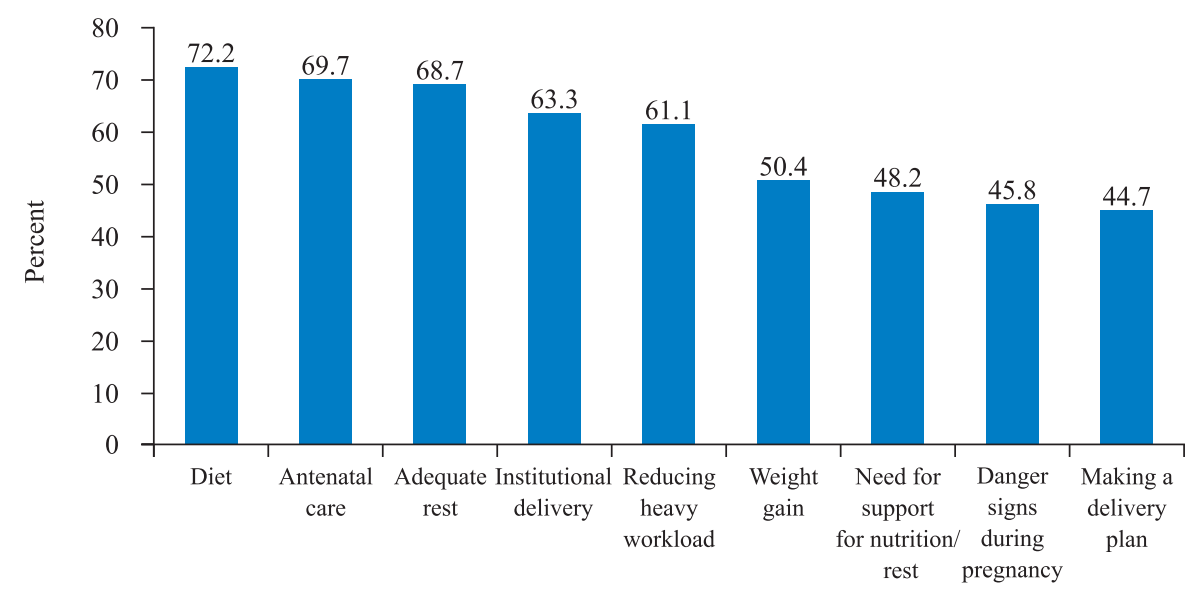

Many women $(\mathrm{N}=263)$ reported that a community organiser had discussed with them issues related to birth planning during the course of the intervention. As can be seen from Table 6, at endline 47 percent of women recalled that a community organiser had provided them information on the need to identify a facility for delivery; and 34 percent and 32 percent, respectively, reported that they had been given information on the need to identify appropriate transport and to save money for delivery-related expenses. 


\section{Table 6:}

Birth planning: Women who recalled information provided by a community organiser on selected topics at endline $(\mathrm{N}=\mathbf{5 0 1})$

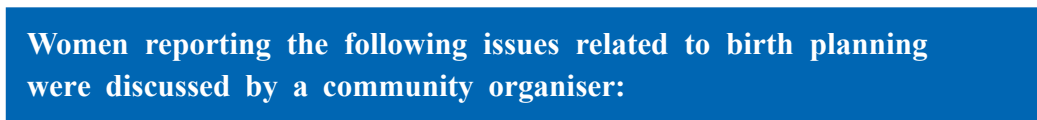

Need to identify a facility for delivery

Need to identify a hospital to go to in case of an emergency

Need to identify mode of transport in case of an emergency

Recognition of danger signs during delivery

Need to save money to meet delivery expenses

Need to decide where to deliver (natal or marital home)

Need to keep clean cotton wool and other necessities ready for use

Need to identify a birth attendant
$\%$

26.4

9.6

\section{Pregnancy-related practices}

Over the intervention period, women reported that they had adopted improved practices during pregnancy, including a reduction in their workload, improved diet and better antenatal care. For example, as compared to women at baseline, women interviewed at endline were more likely to report that they had reduced housework while pregnant ( $54 \%$ of women at baseline vs. $76 \%$ at endline; not shown in tabular form). Findings, reflected in Figure $4 \mathrm{a}$, show that at endline, more women had decreased or completely stopped doing several domestic and agricultural tasks during their pregnancy as compared to women at baseline. Similarly, among women who had more than one pregnancy, a larger proportion of women reported that their domestic workload had decreased or completely stopped during their most recent pregnancy as compared to their past delivery (Figure 4b). 


\section{Figure 4a:}

Work that was reduced or completely stopped during pregnancy, as reported by women at baseline and endline

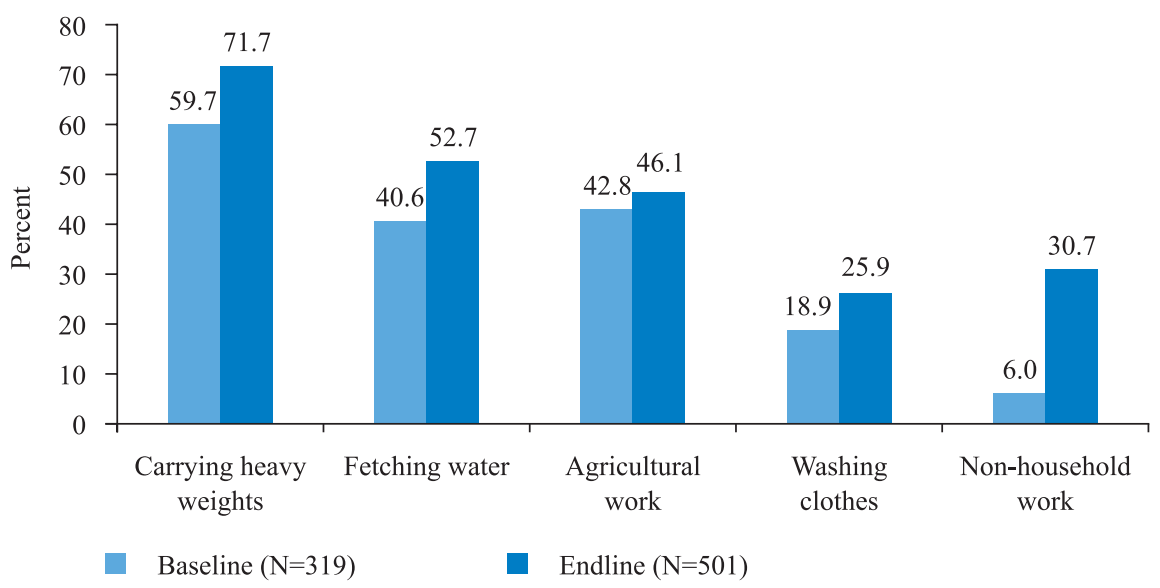

\section{Figure 4b:}

Work that was reduced or completely stopped during pregnancy, as reported by women at endline who had more than one pregnancy resulting in a live birth

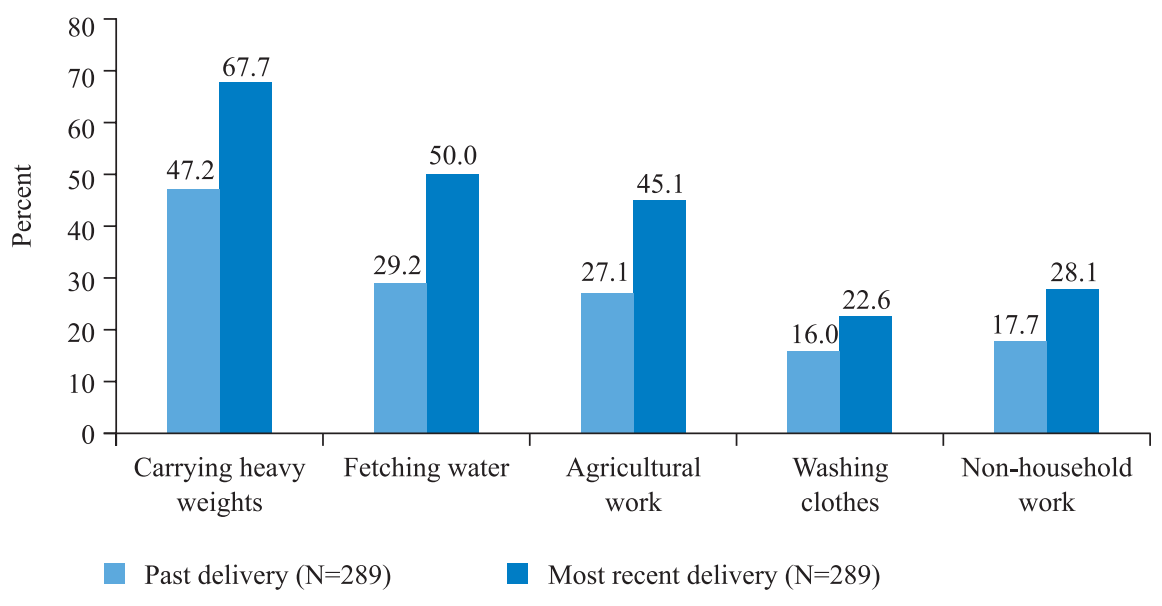


Likewise, diet and nutrition practices improved significantly over the intervention period (Table 7). About two-thirds and one-third of women interviewed at endline $(66 \%$ and $34 \%)$ reported that they had consumed more green leafy vegetables and milk, respectively, 29 percent said that they had eaten more eggs and 31 percent said that they had eaten more lentils (as compared to when they were not pregnant); corresponding figures at baseline were 34 percent, 27 percent, 15 percent and 20 percent. Similarly, women reported that they had eaten more leafy vegetables, drunk more milk eaten more lentils, and eaten more eggs during their most recent pregnancy as compared to their last pregnancy $(66 \%$ vs $34 \%, 34 \%$ vs $20 \%, 29 \%$ vs $16 \%$, and $30 \%$ vs $13 \%$, respectively, for the most recent and last pregnancy). Interestingly, even the proportion of women reporting that they had received nutritional services from the anganwadi centre increased significantly from baseline to endline, and among multiparous women, from the past delivery to the most recent delivery, even though activities with anganwadi workers did not form a major part of the intervention.

\section{Table 7:}

Nutrition practices during pregnancy as reported by women at baseline and endline, and at endline by women who had more than one pregnancy resulting in a live birth

\begin{tabular}{|c|c|c|c|c|}
\hline \multirow{2}{*}{$\begin{array}{l}\text { As compared to when not } \\
\text { pregnant, } \% \text { of women } \\
\text { reporting that during } \\
\text { pregnancy they: }\end{array}$} & \multicolumn{2}{|c|}{ All respondents } & \multicolumn{2}{|c|}{$\begin{array}{l}\text { Women reporting more } \\
\text { than one birth }\end{array}$} \\
\hline & $\begin{array}{l}\text { Baseline } \\
(\mathrm{N}=319)\end{array}$ & $\begin{array}{l}\text { Endline } \\
(\mathrm{N}=501)\end{array}$ & $\begin{array}{c}\text { Past delivery } \\
(\mathbf{N}=\mathbf{2 8 9})\end{array}$ & $\begin{array}{l}\text { Most recent } \\
\text { delivery } \\
(\mathrm{N}=\mathbf{2 8 9})\end{array}$ \\
\hline $\begin{array}{l}\text { Ate more green leafy } \\
\text { vegetables }\end{array}$ & 33.5 & $65.5^{*}$ & 34.4 & $65.6^{*}$ \\
\hline Drank more milk & 27.0 & $33.9 *$ & 19.8 & $34.4 *$ \\
\hline Ate more lentils & 20.1 & $31.1^{*}$ & 16.0 & $29.2 *$ \\
\hline Ate more eggs & 15.4 & $28.8^{*}$ & 12.5 & $29.5^{*}$ \\
\hline $\begin{array}{l}\text { Continued to eat the same } \\
\text { type of food }\end{array}$ & 2.5 & 1.6 & 1.4 & 2.8 \\
\hline $\begin{array}{l}\text { Received supplementary } \\
\text { nutrition from the anganwadi }\end{array}$ & 45.1 & $58.7^{*}$ & 42.7 & $59.4^{*}$ \\
\hline
\end{tabular}

${ }^{*} p \leq 0.001$.

Antenatal practices also improved significantly following the intervention. While in the baseline survey 90 percent of women reported that they had sought at least one antenatal check up, this increased to 96 percent among women interviewed at endline. A similar improvement in antenatal practices was observed among women with more than one birth: while 88 percent of multiparous women reported receiving one antenatal check-up during the previous pregnancy, this proportion increased to 96 percent in the most recent 
pregnancy. There was also an increase in the proportion of women who made three or more antenatal visits $(61 \%$ to $73 \%$ ), the number of women receiving antenatal care during the first trimester ( $45 \%$ to $55 \%$ ), distribution of iron and folic acid tablets $(30 \%$ to $43 \%$ ) and tetanus toxoid immunisation ( $88 \%$ to $95 . \%)$ as reported at baseline and endline. Similarly, among multiparous women, reporting of almost all antenatal care practices increased significantly for the most recent birth as compared to the last birth (Table 8).

\section{Table 8:}

Antenatal practices as reported by women at baseline and endline, and at endline by women who had more than one pregnancy resulting in a live birth

\begin{tabular}{l|l|c|c|c|}
\hline \multirow{2}{*}{$\%$ of women who: } & \multicolumn{2}{|c|}{ All respondents } & \multicolumn{2}{c|}{$\begin{array}{c}\text { Women reporting more } \\
\text { than one birth }\end{array}$} \\
\cline { 2 - 5 } & $\begin{array}{c}\text { Baseline } \\
(\mathbf{N}=\mathbf{3 1 9})\end{array}$ & $\begin{array}{c}\text { Endline } \\
(\mathbf{N}=\mathbf{5 0 1})\end{array}$ & $\begin{array}{c}\text { Past delivery } \\
(\mathbf{N}=\mathbf{2 8 9})\end{array}$ & $\begin{array}{c}\text { Most recent } \\
\text { delivery } \\
\text { (N=289) }\end{array}$ \\
\hline $\begin{array}{l}\text { Had at least one antenatal } \\
\text { check-up }\end{array}$ & 90.3 & $95.8^{*}$ & 87.2 & $95.5^{*}$ \\
$\begin{array}{l}\text { Made more than three } \\
\text { antenatal visits }\end{array}$ & 61.0 & $72.5^{*}$ & 60.2 & $67.0^{* *}$ \\
$\begin{array}{l}\text { Received antenatal care during } \\
\text { the first trimester }\end{array}$ & 45.3 & $54.9^{*}$ & 45.1 & 49.7 \\
$\begin{array}{l}\text { Were given 100 or more iron } \\
\text { and folic acid tablets }\end{array}$ & 30.1 & $42.7^{*}$ & 32.4 & $43.1^{*}$ \\
$\begin{array}{l}\text { Consumed 100 or more iron } \\
\text { and folic acid tablets }\end{array}$ & 13.5 & $16.6^{* * *}$ & 12.5 & $16.3^{* *}$ \\
$\begin{array}{l}\text { Had at least two tetanus } \\
\text { toxoid injections }\end{array}$ & 87.8 & $94.8^{*}$ & 86.1 & $94.5^{*}$ \\
\hline
\end{tabular}

${ }^{*} p \leq 0.001, * * p \leq 0.05,{ }^{* * *} p \leq 0.1$.

In in-depth interviews, health care providers corroborated that pregnancy-related practices had indeed improved over the course of the intervention. For example:

There has been a lot of change in the last two years. A larger number of pregnant women are now visiting the primary health centre. Moreover, they are also following medical advice properly. Earlier, the situation was totally different. If women had a problem, they would go to traditional healers/quacks or use herbal medicine. But now all the women take medicines. To some extent this change is due to the efforts of community organisers. This change was possible because community workers went to the people and made them aware of their rights. (Medical officer, primary health centre, female, 30 years) 


\section{Delivery-related practices}

As noted earlier, the project aimed to increase birth planning and preparedness, and increase institutional deliveries in the intervention area. Findings, presented in Tables 9 and 10, indicate a significant improvement in both practices over the course of the intervention. With regard to birth planning, a larger proportion of women at endline, as compared to baseline, reported that they had decided in advance whether to deliver in their natal or marital home ( $87 \%$ vs. $73 \%$ ); likewise, there was an increase in the proportion of women reporting that they had decided to have an institutional delivery from baseline to endline (from $67 \%$ to $79 \%$ ), identified a facility for delivery ( $40 \%$ to $65 \%$ ), made arrangements for transport ( $28 \%$ to $52 \%$ ), discussed birth-related plans with close family members (34\% to $56 \%$ ), accumulated resources to cover the costs related to the delivery ( $43 \%$ to $68 \%$ ) and identified a hospital to go to in case of an emergency (35\% to $49 \%$ ). The decline in the proportion of women who reported identifying a birth attendant at endline as compared to baseline may be explained by the fact that fewer women planned to deliver at home and hence the need for a trained attendant did not arise.

\section{Table 9:}

Planning for delivery as reported by women at baseline and endline

\begin{tabular}{l|c|c|}
\hline \% of women reporting that they: & $\begin{array}{c}\text { Baseline } \\
(\mathbf{N}=\mathbf{3 1 9})\end{array}$ & $\begin{array}{c}\text { Endline } \\
(\mathbf{N}=\mathbf{5 0 1})\end{array}$ \\
\hline Decided whether to deliver in their natal or marital home & 73.2 & $86.8^{*}$ \\
Decided to deliver in an institution & 67.1 & $78.6^{*}$ \\
Identified a birth attendant & 44.5 & 35.5 \\
Identified a hospital/facility for delivery & 40.2 & $65.3^{*}$ \\
\hline $\begin{array}{l}\text { Identified/decided transport by which to mach the } \\
\text { hospital/facility for delivery }\end{array}$ & 28.0 & $52.1^{*}$ \\
\hline Discussed birth-related plans with close family members & 33.5 & $56.3^{*}$ \\
Saved money to meet delivery expenses & 43.3 & $67.7^{*}$ \\
\hline Identified a hospital to go to in case of an emergency & 35.0 & $49.4^{*}$ \\
\hline$* 00.001$. & &
\end{tabular}

Skilled attendance at delivery also increased over the intervention period. Where necessary, a community organiser accompanied the woman to a facility for delivery ( $10 \%$ of all endline respondents, not shown in tabular form). Interaction with community organisers and the mediating role that organisers played in enhancing women's access to public health services was important, moreover, in strengthening women's confidence in the services provided at primary health centres and hospitals. Indeed, many women $(66 \%)$ reported at endline that they felt more confident talking about their health problems as compared to before the start of the intervention (not shown in tabular form). 
As evident from Table 10, the proportion of women delivering in the home declined significantly from 54 percent among those who had delivered in the 12 months preceding the baseline survey to 38 percent among those who had delivered in the 12 months preceding the endline survey. Likewise, multiparous women were significantly less likely to report that the last delivery had taken place at home as compared to the last-but-one birth (44\% vs $58 \%)$, indicating that even among women who had experienced pregnancy prior to the initiation of the intervention, there was some shift to institutional delivery by the end of the intervention. ${ }^{8}$

Another interesting shift is that more women delivered in government institutions than in private institutions over the course of the intervention, with a significant increase in the proportion of deliveries in the primary health centre ( $8 \%$ to $16 \%$ ) and the government hospital (15\% to $27 \%)$ from baseline to endline. This increase in institutional deliveries should be interpreted as a conservative estimate of change. As mentioned earlier, the universe for both baseline and endline surveys were women who had delivered in the 12 months preceding each survey, that is, those who had delivered between September 2003 and September 2004 and those who had delivered between April 2005 and April 2006, respectively. As a result, not all endline respondents were exposed fully to the intervention - for example, those who delivered in April or May 2005 would not have been exposed to more than six months of the intervention; and likewise, those more fully exposed may not have delivered prior to the endline survey and would not have been interviewed.

\section{Table 10:}

Place of delivery as reported by women at baseline and endline, and at endline by women who had more than one pregnancy resulting in a live birth

\begin{tabular}{|l|c|c|c|c|}
\hline \multirow{2}{*}{ Place of delivery } & \multicolumn{3}{|c|}{ All respondents (\%) } & \multicolumn{2}{|c|}{$\begin{array}{c}\text { Women reporting more } \\
\text { than one birth (\%) }\end{array}$} \\
\cline { 2 - 5 } & $\begin{array}{c}\text { Baseline } \\
(\mathbf{N}=\mathbf{3 1 9})\end{array}$ & $\begin{array}{c}\text { Endline } \\
(\mathbf{N}=\mathbf{5 0 1})\end{array}$ & $\begin{array}{c}\text { Past delivery } \\
(\mathbf{N = 2 8 9 )}\end{array}$ & $\begin{array}{c}\text { Most recent } \\
\text { delivery } \\
(\mathbf{N}=\mathbf{2 8 9})\end{array}$ \\
\hline Home & 54.1 & $38.4^{*}$ & 57.6 & $44.4^{*}$ \\
\hline Primary health centre & 7.9 & $16.0^{*}$ & 9.0 & $15.6^{* *}$ \\
\hline Government hospital & 15.4 & $26.6^{*}$ & 16.3 & $25.7^{* *}$ \\
Private clinic/hospital & 22.6 & $19.0^{* *}$ & 17.0 & 14.2 \\
\hline
\end{tabular}

${ }^{*} p \leq 0.001,{ }^{*} p \leq 0.05$.

8 This is contrary to the usual trend seen in many studies where women who have once delivered at home are more likely to do so in subsequent deliveries as well. 


\section{Summary and recommendations}

\section{Summary}

This report describes an intervention piloted in a mandal in Andhra Pradesh that aimed to improve maternal health outcomes and pregnancy-related care. Activities were focused on raising awareness of better maternal health practices in the community, building support for pregnant women within the family and the community, and creating an enabling environment for pregnant women to access health care services. The intervention recognised the need to target not just pregnant women but also members of the community and the family, notably husbands and mothers-in-law. Multiple strategies were adopted using local field staff, known as community organisers.

The intervention sensitised community members about the importance of maternal health care. It also mobilised local groups, such as gram panchayats and youth committees, and the community more generally, to make public health providers accountable for service delivery. It is evident from the above that the intervention did not directly address providers and facility level obstacles to the provision of services; rather, it focused on empowering the community, pregnant women and their families to demand improved services.

Findings show that community organisers played a pivotal role in empowering gram panchayat members and youth committee members to demand better health services, and influencing pregnancy-related practices at the family and individual level. For example, community representatives supported gram panchayat and youth committee members to organise regular review meetings with health service providers, hold public campaigns and petition government officials. At the family level, community organisers made home visits and organised group meetings to raise awareness about maternal health, build family support for pregnant women and involve husbands in pregnancy-related care. During visits to pregnant women in their homes, community organisers sensitised women to the need for appropriate pregnancy-related care, and supported pregnant women to access pregnancy and delivery services, when required.

As the study findings show, the intervention resulted in changes in pregnancy- and delivery-related practices at the community, family and individual level. Most notable was the increased use of government health facilities; following the intervention, there were more institutional deliveries, and more women reported accessing comprehensive antenatal care. Similarly, birth planning increased, and women reported improved practices during pregnancy including reducing their domestic workload and consuming a more nutritious diet. Family and community support for pregnant women also improved; for example, communities were willing to address the obstacles to accessing services, including lack of transport in an emergency and lack of staff at the health facility. Although husbands were difficult to reach during home visits, husbands' involvement in pregnancy-related care increased, though modestly, over the course of the intervention, with somewhat larger proportions of husbands and mothers-in-law accompanying women for antenatal 
care or providing help in domestic work at the end of the intervention, as compared to the baseline.

However, the limitations of the intervention must be acknowledged and findings should be interpreted with caution. First, this was a demonstration project and did not include a control group; in the absence of a control group, it was not possible to control the extent to which factors exogenous to the intervention may have influenced changes in the lives of the respondents. Second, 18 months is perhaps too short a period to measure the changes that the project sought to attain. Third, as the intervention was conducted in a small setting, it may not be replicable at the state or district level. Fourth, as the survey was conducted by representatives of the NGO, participants may have been hesitant to be critical of the project. Fifth, although several sub-interventions were administered, the study was not designed to assess the relative effect of each sub-intervention; hence we are unable to draw conclusions about which of these were most effective. At the same time, however, the intervention does provide some directions regarding the role of community mobilisation and the use of community organisers in improving pregnancy outcomes and access to health services.

\section{Recommendations}

As the findings show, although the intervention did not focus directly on health care providers or facilities, it succeeded in empowering the community to demand better maternal health services. The experience of the intervention suggests that community groups, such as gram panchayats and community members, are a valuable resource that can be effectively mobilised to promote better health practices. The project has also demonstrated that youth have the potential to take on a guiding role within their communities and enable health system accountability.

Programmes to improve maternal health would need to focus on empowering communities to make health service providers demand-responsive, for example, by organising regular review meetings with providers and setting up gram panchayat committees and youth committees. Indeed, as seen in Mominpet mandal, once communities recognise that health is a priority need, they are ready to contribute, in cash or in kind or in the form of voluntary labour, to improving health outcomes, but programmes would first need to ensure that community groups and community members are mobilised.

At the same time, the intervention shows that it is important to foster a change in the attitude of the family, notably husbands and mothers-in-law, to make them more supportive of pregnant women and to involve them in assisting pregnant women to access health services. Husbands and family members need to be made aware of the key role that they can play in ensuring safe pregnancy outcomes, including participation in birth planning. Important stakeholders, such as husbands, may be difficult to reach as a group, and appropriate strategies need to be adopted to ensure that they are effectively addressed. There is also a need to address deep-rooted traditional gender norms that underscore that pregnancy is a "woman's issue," and that husbands are not required to participate in pregnancy care. 
The intervention clearly highlights the need for a group of community level workers to act as motivators at the grassroots level and as a link between women and the health system. While the National Rural Health Mission (NRHM) has envisioned a similar role for ASHAs (Accredited Social Health Activists), ${ }^{9}$ the ASHA model focuses its interventions on the woman alone. For outcomes to be sustainable, as lessons from the current intervention suggest, the activities of community workers need to go beyond providing only a link to pregnant women and programmes need to work towards building support within the family and the community as well.

The intervention was based on a rights approach, and made safe motherhood a public issue by mobilising local institutions to demand accountability and better services from the health system. These aspects would need to be incorporated in the National Rural Health Mission's ASHA programme.

A key issue raised with regard to intervention projects is their potential for scalability, given that activities need to be intensive and ongoing. However, in the present context where the need for community health workers has been recognised at the national level, as reflected in the formulation of the ASHA programme, it is felt that this model is indeed scalable. With training, the network of ASHAs can play a larger role, linking the community, the family and women themselves, to ensure improved health outcomes.

The benefits of the intervention have been recognised by both the community and the district health authorities, and intervention activities have been sustained even after the project has concluded. At the community level, members have acknowledged the value of mobilisation efforts, and are continuing several project initiatives; for example, gram panchayat meetings are being organised even after elections have been held and new representatives chosen. Likewise, district health authorities have acknowledged the benefits of the intervention and regularly invite representatives of the M.V. Foundation to participate in various health committees. The success of the pilot project has also encouraged the Foundation to expand its activities from a focus on child rights issues to include maternal health; moreover, the Foundation is now replicating this initiative, with the support of community organisers from Mominpet mandal, in seven other mandals in Rangareddy district.

In short, given that pregnancy-related practices and care seeking improved to some extent following the intervention, programmes need to adopt multiple approaches to raise awareness of maternal health care at the level of the community, family and the individual, change pregnancy-related practices, and address traditional gender norms. Indeed, the changes observed in antenatal practices and in institutional deliveries following the intervention are promising, and suggest that such a model of community mobilisation may be effective in improving maternal health outcomes.

9 An ASHA is a community level worker who, in addition to other responsibilities, supports pregnant women to access antenatal care and safe delivery. One ASHA is appointed for every 1,000 population and she is given incentives for each of the tasks she is required to perform. 


\section{References}

Barua, A., R.P. Pande, K. Macquarrie et al. 2004. "Caring men? Husbands' involvement in maternal care of young wives," Economic and Political Weekly 39(52): 5661-5668.

Bhatia, J.C. 1993. "Levels and causes of maternal mortality in southern India," Studies in Family Planning 24 (5): 310-318.

Bloom, S.S., D. Wypij and M. Das Gupta. 2001. "Dimensions of women's autonomy and the influence on maternal health care utilization in a north Indian city," Demography 38(1): 67-78.

Datta, K.K., R.S. Sharma, P.M.A. Razack et al. 1980. "Morbidity patterns amongst rural pregnant women in Alwar, Rajasthan: A cohort study," Health and Population: Perspectives and Issues 3(4): 282-292.

Department for International Development (DFID). 2004. Reducing maternal deaths: Evidence and action <www.dfid.gov.uk/pubs/files/reducmaternaldeath.pdf $>$ accessed on 20 July 2007.

Fathalla, M.F. 2004. "Reproductive rights and reproductive wrongs: The case for maternal mortality," Speech at the National Reproductive Health Summit, Abuja, Nigeria.

Foundation for Research in Health Systems (FRHS). 2004. Community involvement in reproductive health: Findings from research in Karnataka, India. Unpublished.

International Institute for Population Sciences (IIPS). 2007a. National Family Health Survey (NFHS-3), 2005-06. Fact Sheet, Andhra Pradesh, Provisional Data. Mumbai: IIPS.

International Institute for Population Sciences (IIPS). 2007b. National Family Health Survey (NFHS-3), 2005-06. Fact Sheet, India, Provisional Data. Mumbai: IIPS.

Jejeebhoy, S.J. 2000. "Safe motherhood in India: Priorities for social science research," in Women's Reproductive Health in India, ed. R. Ramasubbam and S.J Jejeebhoy. Jaipur: Rawat Publications, pp. 134-185.

Jejeebhoy, S.J. and L.C. Varkey. 2004. "Maternal health and pregnancy-related care," in Looking Back, Looking Forward: A Profile of Sexual and Reproductive Health in India, ed. S.J. Jejeebhoy. Jaipur: Rawat Publications, pp. 44-87.

Khan, M.E., I. Khan and N. Mukherjee. 1997. "Involving men in safe motherhood," Journal of Family Welfare 43(2): 18-30.

McCarthy, J. and D. Maine. 1992. "A framework for analyzing the determinants of maternal mortality," Studies in Family Planning 23(1): 23-33.

Population Research Centre (PRC). 2000. "Rapid Household Survey, RCH Project Phase II (1999): Rangareddy District Report," sponsored by Ministry of Health and Family Welfare, Government of India. 
Rama Padma, G. 2005. "Perceptions on safe motherhood: An analysis of results from rural Andhra Pradesh," Economic and Political Weekly 40(5): 465-473.

Registrar General, India (RGI). 2001a. Primary Census Abstract, Total Population: Table $A-5$, Series 1. New Delhi: RGI.

Registrar General, India (RGI). 2001b. Tables on Houses, Household Amenities ad Assets. Data product no. 00-036-2001-Cen-CD. New Delhi: RGI.

Registrar General, India (RGI). 2006. Sample Registration System: Maternal Mortality in India: 1997-2003-Trends, Causes and Risk Factors. New Delhi: RGI in collaboration with Centre for Global Health Research, University of Toronto.

Sugathan, K.S., V. Mishra and R.D. Retherford. 2001. "Promoting institutional deliveries in rural India: The role of antenatal care services," National Family Health Survey Subject Reports, No. 20. Mumbai: International Institute for Population Sciences; Honolulu: East-West Center, Population and Health Studies.

Thaddeus, S. and D. Maine. 1994. "Too far to walk: Maternal mortality in context," Social Science and Medicine 38(8): 1091-1110.

United Nations Children's Fund (UNICEF). n.d. Building health and hope for soon-to-be mothers in rural India, <http://www.unicef.org/infobycountry/india_fight_mortality.html> accessed on 20 July 2007.

United Nations Population Fund (UNFPA). 2002. Maternal mortality update, 2002:

A focus on emergency obstetric care, <www.unfpa.org/upload/lib_pub_file/

201_filename_mmupdate-2002.pdf $>$ accessed on 20 July 2007.

\section{Acknowledgements}

I would like to thank the women of Mominpet for sharing their lives with us with so much faith. All the participants of the project-including members of youth groups, gram panchayats and women's groups - were a constant source of inspiration. I would also like to thank the team of community organisers and the field staff at the M.V. Foundation, without whose support this project would not have been possible.

I am grateful to Shireen Jejeebhoy, Shveta Kalyanwala, K.G. Santhya and Komal Saxena at the Population Council for their constant guidance and support throughout the project period. I would also like to thank them for convincing me to include a research component in this project, which made the project more meaningful. I am grateful to Radhika Ramasubban and Rajani R. Vaid for reviewing the report and Deepika Ganju for editing the report. 